\title{
106 Weight loss in type 2 diabetes mellitus is associated with decreased myocardial triglyceride content and improved left ventricular function Sebastiaan Hammer*, Marieke Snel, Ingrid M Jazet, Rutger W van der Meer, Johannes A Romijn, Hanno Pijl, Edo Meinders, Johannes WA Smit, Albert de Roos and Hildo J Lamb
}

Address: Leiden University Medical Center, Leiden, The Netherlands

* Corresponding author

from I th Annual SCMR Scientific Sessions

Los Angeles, CA, USA. I-3 February 2008

Published: 22 October 2008

Journal of Cardiovascular Magnetic Resonance 2008, I0(Suppl I):A7 doi:I0.I 186/1532-429X-I0-SI-A7

This abstract is available from: http://jcmr-online.com/content/I0/SI/A7

(c) 2008 Hammer et al; licensee BioMed Central Ltd.

\section{Introduction}

Obesity and type 2 diabetes mellitus (DM2) are risk factors for cardiovascular disease. Weight loss improves myocardial left ventricular systolic and diastolic function and glycemic control. In healthy subjects myocardial triglyceride (TG) pools have proven to be flexible, associated with changes in myocardial function. Whether improvements in myocardial function are associated with changes in myocardial triglyceride (TG) content in DM2 is unknown.

\section{Purpose}

To determine the effects of substantial weight loss in obese DM2 patients on myocardial TG content and myocardial function.

\section{Materials and methods}

Body mass index (BMI) and plasma HbA1c were determined in 9 obese, insulin treated DM2 patients (mean age \pm SE: $48.2 \pm 3.2 \mathrm{yrs}$ ) before and after 16 weeks of a very low calorie diet (VLCD, $473 \mathrm{kcal} /$ day). Furthermore, myocardial TG content and left ventricular (LV) function were determined using proton magnetic resonance spectroscopy and MRI respectively at $1.5 \mathrm{~T}$ (Gyroscan ACS/NT15, Philips). During the intervention all insulin and other anti diabetic treatment were stopped. The percentage (\%) of myocardial TG was calculated as TG/water $\times 100$. Myocardial function was calculated as cardiac output (CO) and ejection fraction (EF). In addition LV mass, blood pressure and diastolic ratio between the early and atrial filling phase (E/A ratio) were determined.

\section{Results}

BMI decreased from $35.8 \pm 1.5$ at baseline to $27.6 \pm 5.0$ $\mathrm{kg} / \mathrm{m}^{2}(\mathrm{P}<0.001)$ after substantial weight loss (mean decrease: $-25.6 \pm 1.5 \mathrm{~kg}$ ), and was associated with a significant improvement in HbA1c (from $7.8 \pm 0.6$ to $6.1 \pm$ $0.4 \%, \mathrm{P}<0.05$ ). Myocardial \%TG at baseline was $0.74 \pm$ $0.10 \%$ and decreased to $0.42 \pm 0.32 \%$ after substantial weight loss $(\mathrm{P}<0.05$, Fig. 1A). CO decreased from $7790 \pm$ 577 to $6552 \pm 402 \mathrm{ml}$ at baseline and after substantial weight loss respectively $(\mathrm{P}<0.05)$. LV mass decreased from $119 \pm 9 \mathrm{~g}$ at baseline to $101 \pm 7 \mathrm{~g}$ after weight loss (P $<0.01$, Fig. 1B). Ejection fraction was unchanged after substantial weight loss. Systolic and diastolic blood pressures decreased significantly from $144 \pm 10$ and $81 \pm 3$ $\mathrm{mmHg}$ at baseline respectively, to $120 \pm 7$ and $71 \pm 3$ after substantial weight loss $(\mathrm{P}<0.01)$. Diastolic $\mathrm{E} / \mathrm{A}$ ratio increased from $1.07 \pm 0.07$ at baseline to $1.24 \pm 0.05$ after weight loss $(\mathrm{P}<0.05)$.

\section{Conclusion}

Substantial weight loss in insulin dependent, severely obese DM2 patients improves glycaemic control and myocardial function. These improvements are associated 

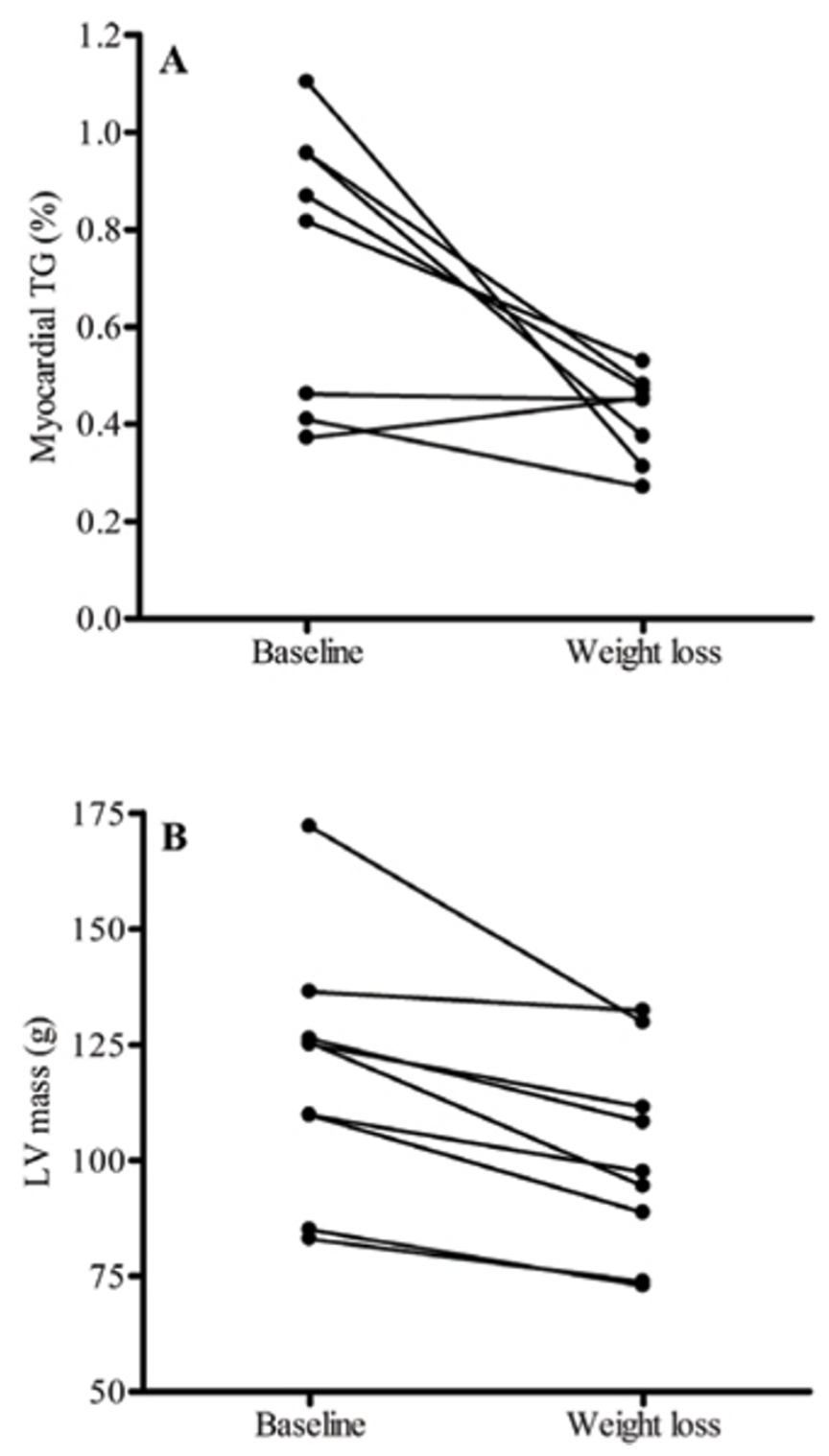

Figure I

Myocardial triglyceride (TG) content and left ventricular (LV) mass are decreased after weight loss. $* P<0.05$. Substantial weight loss in severely obese type 2 diabetic patients is associated with a decrease in myocardial triglyceride content and with improvements in myocardial function.

with a decrease in myocardial TG content. We show for the first time that increased myocardial TG content in obese DM2 patients can be restored by weight reduction. Furthermore, myocardial TG content can be used as a biomarker to evaluate the response of interventions in DM2.
Publish with Biomed Central and every scientist can read your work free of charge

"BioMed Central will be the most significant development for disseminating the results of biomedical research in our lifetime. "

Sir Paul Nurse, Cancer Research UK

Your research papers will be:

- available free of charge to the entire biomedical community

- peer reviewed and published immediately upon acceptance

- cited in PubMed and archived on PubMed Central

- yours - you keep the copyright

Submit your manuscript here:

http://www.biomedcentral.com/info/publishing_adv.asp 